\title{
LINGUISTIC ECOLOGY AS SAFETY FACTOR OF SOCIOCULTURAL CONTEXT
}

\author{
Nadezhda M. Loktionova \\ Department of Foreign Languages \\ Don State Technical University \\ Academy of Construction and Architecture \\ Rostov-on-Don, Russia \\ nad572@yandex.ru \\ Olga A. Fomina \\ Department of Foreign Languages \\ Don State Technical University \\ Academy of Construction and Architecture \\ Rostov-on-Don, Russia \\ lelik8181@list.ru
}

\author{
Lidia K. Alakhverdieva \\ Department of Foreign Languages \\ Don State Technical University \\ Academy of Construction and Architecture \\ Rostov-on-Don, Russia \\ molli47@mail.ru \\ Olesya A. Drozdova \\ Department of Foreign Languages \\ Don State Technical University \\ Academy of Construction and Architecture \\ Rostov-on-Don, Russia \\ olesya_gri@mail.ru
}

\author{
Olga Yu. Potanina \\ Department of Foreign Languages \\ Don State Technical University \\ Academy of Construction and Architecture \\ Rostov-on-Don, Russia \\ olgapotanina2007@yandex.ru
}

\begin{abstract}
The concept of linguistic ecology appeared a few years ago and has already gained its status within the conceptual and terminological system of the Russian language, which currently deals with the evolution of linguistic and cultural values in general. Unfortunately, the concepts of aggression and aggressiveness become ever more popular these days within all fields of human life. People get used to a negative communicative portrait. In this regard, the task of linguistic ecology is to preserve cultural environment and the Russian language as its integral part, to develop and acquire other linguistic preferences for native speakers, especially younger generation, to focus on language ideals, to make people value the acquired linguistic traditions, and as a result, to introduce positive changes in the society, the communication process, and the system of values as such. This is possible only in the context of competently pursued effective language policy. Especially, if this refers to a multicultural and multiethnic region such as the North Caucasus. The issue of linguistic accuracy and political correctness is extremely relevant. The situation of ethnoconflict tension can change considerably under the influence of several factors. Incorrect words or publications in mass media may contribute to ethnic tensions. Therefore, taking into account the above-
\end{abstract}

mentioned facts, one may conclude that the role of linguistic ecology is undoubtedly important.

Key words-linguistic ecology, sociocultural space, modern language situation, aggressive communication, language and speech behavior.

\section{INTRODUCTION}

Recent years are characterized by an emerging tendency to define various landmarks in the language study, which are mainly related to linguistic ideas being reconsidered within interpretation of language problems. However, interdisciplinary study in the field of linguistic ecology remains the closest to reality, relevant, and up to date. Based on the broadest conceptual perception of linguistic ecology as a science closely linked to various sections of linguistics, the paper deals only with relationships of human society with surrounding environment, being the main aspect of sociocultural community.

\section{PURPOSE OF STUDY}

The study of the ecological process of conceptualizing the environment and the person is particularly relevant since 2017 is declared the year of ecology in Russia. "Mankind cannot postpone the solution of environmental tasks any longer, - said the President Vladimir Putin at the meeting of the State 
Council at the Kremlin at the end of 2016. And half measures will not work in this case; otherwise by 2050 the next generations will live in the environment unsuitable for life". This appeal fully reflects the ever-important triad: motherland - language - culture; and covers concepts, which, in fact, make a person a true citizen of one's country and unite the whole nation. The topical complex of linguistic ecology focused on objective development of a language allows mobilizing the main resource of the Russian society, namely spirituality, which is based on spiritual values, spiritual heritage, and spiritual development. As L.A. Verbitskaya fairly noted, "both language and culture as masterpieces of the mankind primarily represent a spiritual and mental process, and only then they are objectified into signs and objects" [1].

\section{PROBLEM STATEMENT}

In general, the in-depth and multidimensional concept of linguistic ecology is focused on preserving the cultural environment and the Russian language integrated into it as the most critical means of human communication. Academician D.S. Likhachev said: "Language is the greatest value of the mankind. It is the language that people write, speak, and think. Think! This should be understood thoroughly, in all polysemy and significance of this fact. It means that the whole conscious experience of a person is bound to his/her native language. Emotions and feelings only decorate our thoughts, or push a thought in some relation, but all our thoughts are formulated through a language ... An educated society was never indifferent to a language. Now it is difficult to meet a person satisfied with the current state of the Russian speech" [2].

Many extralinguistic social factors impact language development. This includes interlingual contacts, language policy, development of economy, science, culture, and social disasters. The changes in the Russian language happening in recent decades reflect "critical, unstable state of our country, which is demonstrated by radical changes in power, economy, world outlook, opposition of estimates, views, way of life, change of values, growth of negative factors" [3]. Lexical and stylistic language deformations, excessive amount of jargons and slang expressions, verbal aggression, a sharp decrease in the culture of the oral and written language of native speakers still deserve special attention of not linguists only, but other representatives of sociocultural community. A language still needs "clarification", "special attention", careful judgment of its cultural originality and solicitous attitude.

\section{MAIN PART}

A variety of new terms and definitions within linguistic ecology that appeared during the last five years only confirm the inexhaustible methodological search for interdisciplinary data that will further foster the understanding of sociocultural language fundamentals: language prediction, language synergy, a heterogeneous language situation, an endoglossic language situation, language divergence, language mixture, language//speech deviation, language vitality, language deficiency, language comfort//discomfort, language conflict, language mediation, language rights, language mistake, isolationism, language stereotypy, language domination, etc. Thus, it may be concluded that linguistic ecology is far beyond the personal analysis; it is more focused on social processes, processes of interaction, cross-cultural communication, and human relationship.

Linguists are the most interested in the process of communication related to speech violations, and, undoubtedly, this makes it socially significant. Manipulations and jargon are studied alongside with media and the Internet containing many negative examples and negative portraits of personality. However, it is believed that there is a certain misbalance in the study of language environment through the ecological approach and its relevance to the concept of "What is bad?": unsuccessful linguistic works of writers, journalists, political and public figures are recorded and advocated.

To maintain safety of sociocultural community, especially educational space, and to increase their cultural component, efficiency, and creativity, it is simply necessary to refocus on the social and communicative concept of "What is good?", and hence to change the language policy towards successful language results. Linguistic ecology covers a variety of fields, including the development of positive language portraits and language personalities that dominate in the Russian classical literature and in modern political discourse. Such personalities shall act as role models for the younger generation. It is believed that such reorientation of linguistic and methodical competences may positively affect the behavior of native speakers.

Obviously, the biggest changes of the modern society are those related to politics and political aspects one way or another. A great variety of modern political talk shows demonstrate aggressive language and speech behavior: hard words, insults, mockery, and sarcasm became a standard of speech. And while listening to those, people are no longer surprised. Unfortunately, in recent years people have got used to negative communicative environment. Every historic period of the country has its political language. The political culture of a current situation is best understood through political language. "The speech makes it possible for subsequent generations to learn facts which were acquired through experience and reflection of previous generations and the best progressive-minded people of the modern era" (L.N. Tolstoy). Political communication was transformed to an extremely aggressive discursive system. At present, politically active people mainly communicate in the language of war and hatred. Politics is always associated with power struggle. A sharp decrease in the level of speech culture in general, jargonization and vulgarization of political speech are naturally caused by the tense sociocultural situation and result in communicative aggression.

Verbal and nonverbal aggression can be considered as a means of manipulation. L.P. Krysin notes that the level of aggression in speech behavior is remarkably high nowadays. The genre of speech is invective, which is characterized by diverse negative assessment of behavior and identity of the addressee: from evocative words and expressions within literary word usage to roughly colloquial and impaired 
lexicon, became ever more typical. All these features of the modern oral and, to some extent, bookish written language result from negative processes of extralinguistic reality; they are closely linked to a general destructive phenomenon of culture and morality [4]. Many modern words, which several years ago were considered "offensive", are now widely used and perceived by different social groups as a norm of communicative behavior.

There are many definitions of communicative aggression. The most complete and substantial of them is the definition by O.N. Zavyalova, who describes verbal aggression as "a form of speech behavior aimed to insult or cause deliberate infliction to a person, group of people, organizations or society in general. Speech aggression is motivated by aggressive speaking and often aimed to cause or support aggressive behavior of the addressee, therefore speech aggression is perceived as the violation of ethical and speech norms" [5]. Intonation, mimic and gestures are traditionally considered as nonverbal signs of communicative aggression.

Linguistics distinguishes instrumental and hostile language aggressions. The instrumental language aggression is mainly used to achieve any discursive objective. According to its expression, this aggression is implicit and is achieved through hidden negative intensions of the speaker. Hostile language aggression is explicit aggression with an obvious intension to harm, offend, humiliate and even offend the opponent.

Particular attention shall be paid to interpretation of aggression offered by A.P. Chudinov. Let us list some of its forms. A.P. Chudinov identifies the following forms of aggression in a modern political discourse:

1. Appeal to physical aggression and metaphoric features of political actions presented as physical aggression.

2. Use of invectives (abuses, insults).

3. Negative assessment of political opponents expressed in a rough, ironical, and ambiguous form.

4. Use of special signs of agony, including extremity, impairment of importance, mistrust to sincerity of the opponent and to reliability of his/her comments.

5. Anxiety, uncertainty, feeling of excessive dependence of personality on the state and society, dissatisfaction with the situation in the country and fear of the future [6].

Mass media became a tool of influence on the public consciousness. As scientists note, "in media, such functions as influence and conviction begin to replace other language functions, and thus mass media become a means of mass influence" [7]. New tendencies in the culture of speech caused by liberalization of public relations and democratization of Russian literary language standards make the problem of Russian language ecology, verbal aggression in society, in general, and in media, in particular, especially relevant.

There is a need to study forms and means of speech aggression in media due to the fact that in its perception of speech standards, the modern Russian-language community in many respects is guided by the language of mass media. In this case, language extremism of mass media contributes to the growth of speech aggression in public communication and promotes the development of acute conflict social environment.

Mass media provide the society with vicious examples of speech behavior when aggression is embedded into the language personality. The aggression of speech behavior of a journalist can distort a picture of the addressee's world, have negative impact on his/her language taste, and provoke reciprocal aggression, which has already been observed for quite a long period.

Liberalization of public life and declaration of freedom of speech generated a lot of conflicts caused by the use of speech products. These are the conflicts induced by verbal insults, slander, and dissemination of data discrediting honor, dignity and business reputation. Now there are new notions related to new aspects of language use in media: offense, insult, language conflict, which demonstrate invective nature of a language, language manipulation, suggestion, linguistic ecology, and speech aggression. There is an urgent need to impose legal restrictions on such notions.

When characterizing a modern media discourse, scientists note its expressional and evaluative character, pragmatic focus, the information and influencing functions, which are established through particular language scenarios and a combination of expression and standard. In this respect, political bias of a media text is critical. It is the transfer of information followed by social assessment [8].

Reinforcement of democratic tendencies in the society and the language led to consolidation of informal conversation and to intensification of colloquial speech. The influence of informal speech on public communication "has sharply increased by the beginning of the $21^{\text {st }}$ century when the Russian culture and language faced "a change of literary language standards": the written fiction language lost its standard-setting importance and thus moved this function towards oral speech of national public channels" [9]. The priority of a voice speech (radio, television) was followed by the loss of a standard written language due to the increasing role of the Internet. Democratization of publicistic style and expansion of standard boundaries of the mass media language led to deviations in the literary standard of the Russian language.

"Live transmission showed spontaneous oral speech with inevitable errors on television $\langle\ldots\rangle$ that led not only to their dissemination among the population, but also to their authorization" [10]. The 1990 s of the $20^{\text {th }}$ century are also characterized by active language jargonized character, which was mainly caused by the decrease in the level of culture and unavailability of vocational training for new journalists, as well as misinterpreting language democratization. "Such freedom of the Russian speech, removal of all speech taboos, deliberate (in its fight against the Soviet formality) replacement (for the same purposes) of literary words with nonliterary ones made a written language of newspapers a mirror of illiterate speech" [10]. 
The following phenomena of modern Russian media language belong to negative outcomes of the "freedom" of speech:

1. Live transmission and censorship ban cleared the oral speech from earlier accepted restrictions, which led to a decrease in the level of media speech culture and changed its focus to informal and colloquial speech.

2. Common rude nature of speech, wide distribution of the obscene language in different social groups are mainly caused by mass media.

3. Penetration of informal speech elements into TV and radio speech changed speech standards. "Mixture of styles observed at the end of the $20^{\text {th }}$ century made the population lose the idea of functional and stylistic differentiation of the literary Russian language" (Sirotinina O.B., Kostomarov V.G.). The lofty level of discourse almost disappeared from the Russian language. Scientists note "the tectonic shift" of functional styles: the lofty level of the discourse and pathetic language was sharply narrowed and replaced with the neutral style, which, in turn, was replaced by colloquial elements of the national Russian language [9].

The sound language policy in Russia minimized the abovementioned processes. Thus, after adoption of the law "On the national language of the Russian Federation" (2005), there was a gradual elimination from media texts of negative consequences of the "freedom" of speech: the invective and obscene, as well as rough colloquial and slang language, was used less.

A special focus of linguistic ecology is placed on linguistic expertise, i.e. the area of linguistics, which regulates language study of oral and/or written texts regarding issues of particular interest and knowledge in the field of linguistics, speech and legal studies. The infingement of freedom of speech and freedom of expression in media quite often leads to undermining reputation and authority of state power and justice. Without the evidence-based conclusion of judicial linguistic examination 6 such cases are unlikely to have any judicial prospects. The subject of judicial linguistic examination is to establish circumstances, subject to proof regarding a particular case, through solving issues demanding special knowledge in the field of linguistics. Objects of linguistic examinations include units of the language, speech, texts broadcasted by any tangible medium.

Linguistic examination always implies differentiation of information presented as statements and judgments, as well as facts and subjective opinion of the author of the text, thus using the language and the speech means of communication. It should be noted that assessment (facts, events, persons) and judgment are the judgments containing a subjective opinion in a certain form. Expression of assessment is distinguished in the text upon presence of certain words and structures, for example, emotional and expressional phrases where one can distinguish the elements of "good / bad" or their varieties ("kind", "angry", etc.). Positive assessment may imply positive information, while negative assessment covers negative information. Judgment cannot be checked for compliance with reality (unlike data containing asserted facts).

Generally, experts differentiate between descriptive statements and judgments. Descriptive statements contain facts and events; they describe a situation or state, the necessary link between phenomena. Grammatically they are presented as declarative clauses and are subject to verification, i.e. compliance with reality (validity or falsehood). Descriptive statements cannot be offensive, but they can be disproved in case they are discrediting and false. Judgments state an absolute or relative value of any object. Assessment of an object is not subject to refutation. But it can be challenged within the same or other scale of values. Evaluative statements can be negative and positive. They are offensive if they contain obscene words and expressions, the abusive, obscene language, which is directly addressed to or characterizes any particular person.

The paper does not seek to study linguistic examination as a relatively new scientific discipline. However, the area of linguistics is similar to problems of ecology, logically fits within the ecological paradigm of knowledge and has great prospects of social development. The discipline Linguistic Ecology: Theory and Practice is similar in its content to the basic course Fundamentals of Stylistics and Standard of Speech and, in fact, serves to continue and expand the latter one. The discipline is aimed to unveil the issues of contents, the conceptual and terminological system and methodology of a new linguistic discipline. It studies language environment in its dynamics, primarily factors negatively influencing the development and functions of a language, as well as methods to enrich the language and improve its speech practice. The crisis state of the modern Russian society, which is reflected in the Russian language in various dimensions and which, at the same time, influences the language conditions, highlights the importance of the suggested discipline not only from the theoretical perspective, but also from the practical point of view since the materials used throughout the course can form the basis for evidence-based language politics in mass media and various spheres of politics, education, urban development, etc.

\section{V.FINDINGS}

The concept of linguistic ecology includes a wide range of interconnected and interdependent problems. The language ecology and the word ecology go alongside with thinking ecology, moral ecology, culture ecology, etc. It is assumed that knowledge within the modern concept of linguoecology shall be acquired through philological disciplines at secondary and high school. The linguoecological aspect of teaching has a high educational potential, thus forming skills of careful attitude to a language. It also fosters the understanding of the Russian language as the national property demanding protection; forms speech culture of conflict focused on constructive settlement of conflict speech situations; contributes to a balanced and well-considered approach to selection of language means, especially within the multinational environment; fosters patriotism and tolerance through the attitude to the native language. 
For example, one of important elements of Linguistic Ecology and Linguistic Safety is to learn legal consequences of language conflicts related to civil cases concerning the protection of honor, dignity and business reputation (Art. 152, Civil Code of the Russian Federation), criminal cases against slander and insult (Art. 129, Criminal Code of the Russian Federation), against appeals to extremist activity, hostility or hatred, against violation of human dignity (Art. 280, 282, Criminal Code of the Russian Federation), as well as against other signs stipulated in the Federal Law "On Countering Extremist Activities".

Within a multicultural and multiethnic region as the North Caucasus, the issues of "linguistic correctness" and "political correctness" are extremely relevant. Ethnoconflict tensions may lead to fast changes under the influence of several factors. An incorrect word or publication in media devoted to ethnic problems can contribute to ethnoconflict tensions.

"Even a single word in such delicate field as ethnic relations can trigger the conflict, and on the contrary, an appropriate word can promote de-escalation of conflicts" [11]. It should be noted that sometimes under the conditions of ethnoconflict tensions, economic and social issues are perceived from ethnical perspective. Within the corresponding communication context even domestic disputes, when used with ethnicity markers in their invective sense, are qualified as ethnic violation of honor and dignity and have legal implications.

This is also demonstrated by linguistic examinations carried out by the experts of North-Caucasus Federal University. The incorrect statements giving rise to language conflicts can serve as formal indicators of violation of the law and as means of ethnoconflict mobilization of the population. For this reason every native speaker has to be aware of ethical and legal consequences of speech aggression and hostile statements, to be able to simulate situations thus avoiding language aggression and to choose ways of tolerant speech behavior.

\section{CONCLUSION}

Thus, the formation of the linguoecological mindset in the Russian society contributes to the development of humanities and language culture of the personality, and moreover of the personality for whom cultural and spiritual values and language preferences are integrated into the harmonious sociocultural community and ensure its safety and sustainability.

\section{References:}

[1] L.A. Verbitskaya, Let's speak correctly. Study manual, M.: Higher school, 2001.

[2] D.S. Likhachev, "Oral and written language, as well as old and new," Novosibirsk Diocesan Bulletin, No. 2 (63), January, 2007.

[3] D.M. Potsepnya, Changes in dictionary structure of Russian and new lexicographic ideas, Modern language processes. Interuniversity collection, SPb., 2003.

[4] L.P. Krysin, "Some changes in Russian of the end of the 20th century," Study of Slavic languages, No. 5, Seoul, pp. 34 - 91, 2000.
[5] O.N. Zavyalova, Speech or language aggression in the Russian language. Retrieved from http://iamruss.ru/rechevaya-ili-yazykovayaagressiya-v-russkom-yazyke.

[6] A.P. Chudinov, Political linguistics, M.: Flinta, 2006.

[7] S.V. Ilyasova, Language games in communicative space of media and advertising, M.: Flinta: Science, 2009.

[8] E.A. Pokrovskaya, "Role of prose of the sixties in the development of literature language within nonclassical paradigm," Political linguistics, No. 18, 2006.

[9] V.V. Khimik, Disease of a language or language of a disease? Modern Russian speech: state and functioning, Issue II, Collection of analytical materials, Under the editorship of. SPb., 2006.

[10] O.B. Sirotinina, Communication in a risk zone and tendency to diffusion of values, Problems of speech communication: Interuniversity collection of scientific works, Saratov: Saratov Publishing House, Issue 12, pp. 5$13,2012$.

[11] V.A. Avksentyev, I.O. Babkin, N.P. Medvedev, A.Yu. Hots, V.V. Shnyukov, Stavropolye: ethnoconflictological portrait. Collective monograph, Preface and scientific edition of the doctor of sociology, Stavropol: SGU Publishing House, 2002.

[12] E.I. Koryakovtseva, Language of modern Russian press: barbarisms and slang expressions as signals of speech aggression, Wspolczsena komunikacija jazykowa. Prace. Slawistyczne 125 SOW, Warszawa, 2008.

[13] I.I. Skachkova, Language policy and language planning: definition of concepts. Scientific library http://cyberleninka.ru/article/n/yazykovaya-politika-i-yazykovoeplanirovanie-opredelenie-ponyatiy\#ixzz4WhIeE8gF

[14] Sushchenko, E.A., "Reference dictionary of linguoecological terms and concepts," International journal of experimental education, No. 2, 2012.

[15] A.V. Moiseenko, Ecological principles of text description. MGOU bulletin. Series: Russian philology, No. 5, 2015.

[16] G.G. Molchanova, Lingvoecology and current state of a language, MGOU bulletin. Series: Linguistics, 2016, No. 2.

[17] V.B. Gulida, "Conference "National Linguistics": view of native speakers," Issues of linguistics, No. 5, 2013.

[18] V.M. Alpatov, What and how does linguistics study? Issues of linguistics, No. 3, 2015.

[19] M.Yu. Pupynina, A.A. Syuryun, Conference "System changes in languages of Russia", Issues of linguistics, No. 4, 2015. 